\title{
TUDO JUNTO E MISTURADO: APROXIMAÇÕES ENTRE GUIMARÃES ROSA E MILTON NASCIMENTO
}

\section{ALL TOGETHER AND MIXED: APPROXIMATIONS BETWEEN GUIMARÃES ROSA AND MILTON NASCIMENTO}

Vinícius José Fecchio Gueraldo ${ }^{1}$

\begin{abstract}
Resumo: Guimarães Rosa e Milton Nascimento são artistas intimamente ligados a Minas Gerais. Propõe-se aqui uma comparação entre as suas obras, não tanto pelo tema, mas pela lei estética que as organizam, aquilo que Walter Benjamin chamou de forma interna, que são muito semelhantes em seu teor. Dessa aproximação, buscar-se-á pensar as similaridades e as diferenças entre as produções e, por conseguinte, a maneira como essas leem as contradições da nossa chamada modernização conservada.
\end{abstract}

\begin{abstract}
Guimarães Rosa and Milton Nascimento are artists closely related to Minas Gerais. It is proposed here is to compare their works, not from the aspect of the theme, but for the aesthetic law that organize them, that Walter Benjamin called Inner Form, which are very similar in its content. From this approach, we will seek to think about the similarities and differences between their productions and, therefore, the way in which they read the contradictions of our so-called conservevative modernization
\end{abstract}

Palavras-chave: João Guimarães Rosa; Milton Nascimento; Forma interna; Crítica materialista; Modernização conservadora.

Keywords: João Guimarães Rosa; Milton Nascimento; Inner Form; Materialist critique; Conservative modernization.

Guimarães Rosa é o mais notório escritor das Minas Gerais; Milton Nascimento, seu cantor mais célebre - a despeito de ser carioca de nascença. Ambos são reconhecidos por criarem obras intimamente ligadas ao universo mineiro, dando-lhe expressão estética por meio de seus personagens, suas sonoridades, sua ambientação; ao mesmo tempo, no entanto, suas produções não são enquadradas na caixa dos regionalismos em sentido estrito, tal como ocorre, por exemplo, com Coelho Neto na literatura ou Luiz Gonzaga, no âmbito do cancioneiro nacional. Não custa lembrar pela enésima vez que Rosa diz, por meio de Riobaldo de Grande Sertão: veredas (1956), que "O sertão é do tamanho do mundo" (ROSA, 1994, p. 96), ou, na sintética formulação de Antonio Candido, "O sertão é o Mundo" (2002, p. 139). Nas canções gravadas por Milton Nascimento, ouve-se, em "Para Lennon \& McCartney" (Lô Borges/Fernando Brant/Márcio Borges): "Sou do mundo, sou Minas Gerais"

1 Doutorando em filosofia pela Faculdade de Filosofia Letras e Ciências Humanas (FFLCH-USP), mestre em filosofia pelo Instituto de Estudos Brasileiros (IEB-USP) e graduado em filosofia pela Faculdade de Filosofia Letras e Ciências Humanas (FFLCH-USP), todos pela Universidade de São Paulo (USP). Tem experiência na área de Filosofia, com ênfase em Estética, atuando principalmente nos seguintes temas: canção popular brasileira, crítica de arte e filosofia contemporânea. Além disso é professor de musicalização infantil e cordas dedilhadas na Oficina de Música Sonia Silva. 
(NASCIMENTO, 1970). Ivan Vilela tomando o emblemático projeto coletivo Clube da Esquina, de 1972, como caso exemplar, indaga, retoricamente, "se esse álbum não seria o percursor de um procedimento que, mais de uma década depois, receberia o nome de World music." (2010, p. 19).

A despeito dos quase vinte anos que separam suas produções, o intuito aqui é propor uma aproximação entre as criações desses dois artistas que trabalham a matéria social brasileira pelo olhar, digamos assim, mineiro. Mas o enfoque não se debruçará tanto no tema propriamente dito, mas na estruturação formal, na lei que serve de fundamento à organização da obra. Tomando as palavras de Walter Benjamin, na "forma interna" (2011, p. 17).

Em um estudo de 1915 no qual o filósofo se põe a tarefa de comparar dois poemas de Hölderlin, ele estabelece, por meio desse tipo de crítica que busca a "unidade sintética" de "cada criação particular" (2011, p. 15), que "esses poemas são comparáveis. Estão ligados por tal afinidade que se poderia falar de diferentes versões de uma mesma obra" (p. 18-19). Assumindo um vocabulário típico do primeiro romantismo alemão, tal como presente em Novalis, citado no texto em questão (p. 15), ou em Schlegel, que é o principal autor de estudo de sua tese de doutoramento sobre o conceito de crítica no romantismo alemão, Benjamin assume a poesia - o "poetificado" (p.14) - como espécie de metonímia para todas as artes. Como fica claro no fragmento 239 do Athenäum, no qual Schlegel diz que "tudo deve ser poetizado, de modo algum como intenção dos poetas, mas como tendência histórica das obras", ou seja, é "na mescla de todos os gêneros artísticos (...) que está a exigência de que só haja uma única poesia, como também uma única filosofia" (1997, p. 89). Ou seja, todas as referências à poesia, ao lírico, etc. podem e devem ser estendidas à obra de arte como um todo, seja ela escrita em prosa, pintada ou cantada.

O que importa aqui é atentar para quais elementos essa concepção de crítica se interroga, ou, pela negativa, sobre o que ela não se interessa: "nada do processo de criação lírica, nada da pessoa nem da visão de mundo do autor será aqui investigado" (BENJAMIN, 2011, p. 14), isto é, não se trata de propor uma conexão entre vida pessoal e obra, entre posicionamentos públicos e criação artística, entre autoanálise (tão adorada por Rosa) e crítica, pois essa se baseia na "objetividade concreta", na "esfera particular e única na qual repousa a tarefa e a condição do poema" (p. 14). Tampouco os diversos componentes tomados em si mesmos servem para a análise, muito menos para a comparação entre obras. É na organização do todo, ou melhor, na lei que rege esse universo criado, que o "poetificado" específico de cada criação pode ser encontrado - "não importam os elementos, mas sim as relações, uma vez que o próprio 'poetificado' é uma esfera da relação entre obra de arte e vida" (p. 17) - e, dessa maneira:

o que permite a comparação entre os poemas não é a igualdade de um elemento, mas tão só a ligação numa função, a qual encontra-se no único princípio funcional que pode

Revista Crioula - $\mathbf{n}^{\circ} \mathbf{2 6}$ - Relações entre literatura e música na produção de língua portuguesa 
ser assinalado, isto é, o "poetificado". Deve-se comparar o 'poetificado' de ambas as versões - não em sua igualdade, que não existe, mas em sua "comparabilidade". Os dois poemas estão ligados em seu "poetificado" e, a saber, por uma atitude para com o mundo (p. 43).

Não está em questão, na aproximação proposta adiante, o fato de ambas as produções, de Milton Nascimento e de Guimarães Rosa, apresentarem inúmeras referências ao sertão mineiro, tema por excelência do último, e bastante abundante no primeiro (passando do carro de boi pelas fazendas, da congada aos tambores etc.), como explícito já no seu álbum inaugural. Ouvir, por exemplo, "Morro Velho" (1967), na qual se escuta "um toque de violão agudo, solado à maneira de uma viola caipira", sonoridade que apesar de "camuflada por instrumentos de cordas e bateria, envolvia todo o desenrolar da canção, sustentada em um ritmo lento semelhante a uma toada" (DINIZ, 2012, p. 34). Sobre a qual se escuta: "O sertão da minha terra".

Uma enormidade de outros recursos poderiam ser elencados, como a constante aparição das figuras de criança, a rememoração, eventos que se desenrolam em pequenas cidades, os "cronotopos da travessia e da comunhão" para utilizar a expressão de Harlon Sousa (2018). Mas insisto, não é disso que se trata. A tempo: não quero dizer que outras aproximações não sejam possíveis ou mesmo que possam gerar mais frutos, apenas quero destacar a "comparabilidade" das leis imanentes que subjazem a essas produções.

Para tanto, não me arrisco a novas interpretações, me atenho a apresentar um certo consenso crítico que parece aproximar essas produções em sua "sobrevida": a existência da obra de arte é inseparável de sua crítica - e de sua tradução - que lhe explicitam e conferem novas potencialidades (BENJAMIN, 2018, p.89 e 121).

\section{Mundo misturado e a promiscuidade musical}

Nas estórias de Rosa, como o próprio gostava de chamá-las, se encontra “de tudo", como disse Davi Arrigucci Jr., "da bíblia, de Dante, de Shakespeare, de uma infinidade de outros grandes autores, de filósofos e místicos, dos viajantes estrangeiros que andaram pelo sertão, e sobretudo da tradição literária brasileira" (1994, p. 12). Luiz Henrique Garcia escolhe a figura do mosaico para traduzir a experiência sonora do Clube da Esquina - conjunto de artistas capitaneados por Milton Nascimento que atuaram coletivamente durante a década de 1970, que a pesquisadora Sheyla Diniz, na esteira de Raymond Williams, identificou como uma formação cultural (2012, cap. II) - que contava, entre outras coisas, com "uma combinação plural de sonoridades e referências musicais que iam do regionalismo ao jazz, do samba tradicional ao rock progressivo, da bossa nova à canção latino- 
americana" (GARCIA, 2006, p. 200).

Além desse mundo de referências, o que mais chama atenção dos que se debruçam sobre a produção, seja a rosiana, seja a miltoniana, é o alto grau de experimentalismo formal das duas. Guimarães cria uma linguagem única e inconfundível que funde em neologismos latim com sotaques regionais, português arcaico e alemão, como é o caso do famoso "nonada" que abre Grande Sertão: veredas (1994); a sonoridade de Milton, por usa vez, junta música atonal e pequenas melodias pentatônicas, ritmos da congada mineira com timbres do rock progressivo da época, numa fusão sonora única. A introdução com fortes tendências atonais seguidas do coro das crianças em "Ponta de Areia” é um dos inúmeros exemplos possíveis (NASCIMENTO, 1975).

Desde a contemporânea crítica "O homem dos avesso" de Antonio Candido (2002) ao mais famoso romance de Rosa, passando pelo hoje clássico ensaio de Arrigucci Jr, "O mundo misturado" (1994), até o extenso estudo de Willie Bollie Grandesertão.br (2004) muito já se disse sobre a junção de formas na escrita rosiana. Candido atentou, por exemplo, para a transformação do mapa quase documental do norte de Minas que, apesar da enorme precisão que "parece esgotar-se na observação", logo, revela-se impossível, apresenta saltos de contiguidade, "aos poucos vemos ressurgir um universo fictício à medida que a realidade geográfica é recoberta pela natureza convencional" (p. 124), a ponto da topografia assumir função narrativa: dois mundos se separam na sua união, seja nas diferentes margens do rio São Francisco, de um lado, o mundo da amizade, da justiça; do outro, da vingança, do pacto com o demônio. Outro caso exemplar é a travessia do Liso do Sussuarão, impossível na primeira tentativa, e facílima no pós-pacto. Sobrenatural e geográfico são inesperáveis. Bollie alertou para a ambivalência do narrador como sendo alguém ora parte integrante do sistema jagunço, ora operador de um distanciamento crítico que o direciona ao mundo alheio ao sertão (p.142): narrador "dialético e luciférico, é construído de tal modo que ele se situa ao mesmo tempo dentro e fora do sistema de poder" (p. 143).

Como se vê, nesse universo tudo é misturado. Um último aspecto. Trata-se de uma estória baseada na narração tradicional, nos causos que alimentam e são alimentados pela comunidade, cuja existência serve aprendizado à comunidade, ensinamento pela troca de experiência ou, pelo contrário, trata-se de seu oposto, o romance de burguês que nasce do indivíduo isolado e que descreve suas vivências pessoais, sua narração não faz mais parte da vida comum, ele conta o seu desenvolvimento, sua função já não é mais ensinar, mas partilhar a maneira pela qual ele (o personagem) se constituiu desse jeito? Essa é uma das questões levantadas no ensaio de Arrigucci (1994, p. 22-24), à que ele responde: os dois ao mesmo tempo. Riobaldo, o personagem-narrador, em alguns momentos, é a expressão arquetípica dos narradores anônimos da épica oral sertaneja ao contar diversas estórias de jagunços, mas, no olhar geral sobre esse grande diálogo de um lado só (o interlocutor, o doutor da 
cidade, embora esteja ali, nunca assume a palavra - sabemos de sua presença, mas a narração não passa de um monólogo entrecortado), o que se estrutura é um atípico romance burguês de formação desse jagunço aposentado que é Riobaldo, seus amores, suas travessias, sua transformação, sua busca por vingança etc. "Como história do esclarecimento de um destino individual, o romance se vê obrigado a retomar o começo para tentar responder as perguntas sobre o sentido dessa travessia solitária e enigmática, que, no entanto, não podem ser respondidas" (ARRIGUCCI JR., 1994, p. 28.). Princípio estético dito já de maneira lapidar na apresentação de Augusto Matraga, estória de Sagarana, o primeiro livro de Guimarães Rosa, de 1946: "Matraga não é Matraga, não é nada. Matraga é Estêves. Augusto Estêves, filho do Coronel Afonsão Estêves, das Pindaíbas e do Saco-da-Embira. Ou Nhô Augusto" (2001, p. 363.)

No outro lado da nossa comparação, as criações de Milton Nascimento, apesar de toda a diferença - que será apontada -, também se estruturam sobre a regra da mistura ou, nos termos de Ivan Vilela, por uma "promiscuidade", que tem com uma de suas marcas o fato das pessoas tocarem não "apenas o seu instrumento de especialidade, mas sim outros instrumentos que não os que mais dominam. Isso faz com que a sonoridade seja diferenciada por um aspecto sonoro que hoje é chamado de etnomúsica" (2010, p. 23). Em outros termos, ao executarem instrumentos que não estão plenamente familiarizados, por possuírem uma técnica menos apurada, novos sons são produzidos, soluções tímbricas inusuais são encontradas, uma "sonoridade específica", na expressão cunhada por Thais Nunes (2005), começa a se delinear.

Qualquer ouvinte atento que acompanha as faixas do álbum mais aclamado pela crítica, o já referido Clube da Esquina (1972) percebe uma contradição: os fonogramas são muito distintos entre si e, na mesma medida, o disco se encadeia de maneira muito fluida, quase como se fosse uma grande música com diversos momentos.

Isso se deve a vários fatores simultâneos e concatenados. Em primeiro lugar, cada composição tende a se construir em um estilo diferente. Ora ouvimos um rock, ora uma canto latino; por vezes temos uma música lenta instrumental, por outras, um pop adolescente; e assim por diante. No entanto, outros elementos auxiliam na sensação de unidade, como os centro tonais (tanto em canções propriamente tonais, quanto nas modais), que são próximos, "predominantemente lá, ré, sol, dó" (NUNES, 2005, p. 96), isto é, se utilizam de uma gama de notas bastante grande em comum criam unidade, o que não ocorreria se os centros tonais fossem muito afastados entre si, situação na qual a separação entre as faixas seria salientada. Seguindo a linha da unidade, pode-se destacar a combinação dos andamentos, na qual "um momento lento é compensado por um rápido e vice-versa (...). Há inclusive a exploração da mudança pontual de andamento no interior de algumas músicas" (p. 91). As proto-canções gêmeas, por serem quase um fragmento de composição, "Saídas e bandeiras 
$n^{\circ} 1$ e n`2" são a mesma composição com arranjos quase idênticos, mas com letras diferentes e cada uma é a quarta faixa do lado A de seus respectivos LP (trata-se de um álbum duplo). Um último caso exemplar é o retorno da parte C de "Cais" (a segunda faixa do álbum) ao final de "Um gosto de sol" (última faixa do lado A do segundo LP, ou lado C, caso se queira). No entanto, esse retorno do mesmo se faz com nova roupagem, o piano que apresentara o tema em ostinato soa bem ao fundo da gravação, sendo que agora as cordas tomam a frente. Isso para não entrar na recorrência do mesmo que aparece diferente como nos temas e figuras poéticas que atravessam o álbum, nas referências às situações climáticas associadas ao signo da mudança, da estrada, do caminho. Em suma, "o disco flui como se a costura que liga uma música à outra fosse feita por pontos invisíveis" (VILELA, 2010, p. 22).

Como se nota, há inúmeras ligações, o que não implica em um nivelamento no sempre igual. Antes o contrário, tudo o que conecta o álbum é sempre uma mutação do mesmo - a mudança da letra, a citação em outro instrumento. Esse aspecto do convívio do diferente é uma das marcas características da produção de Milton Nascimento (MENEZES JR., 2016, p.138.). Um elemento de suma importância nessa lei que rege esse mundo é a forte divisão dos instrumentos entre os canais direito e esquerdo na mixagem. Por vezes se ouve um instrumento somente em um dos canais, o que obviamente implica em sua total ausência no outro canal, que geralmente é ocupada por outro instrumento, estabelecendo assim um diálogo quase escondido, como pode ser notado logo na primeira faixa do álbum, "Tudo o que você podia ser": violão inteiramente à direita, e guitarra somente na esquerda. Em casos extremos um dos canais pode não conter virtualmente som nenhum, como ocorre na já mencionada parte $\mathrm{C}$ de "Cais". Outro recurso que estabelece o convívio de elementos estranhos entre si e muito comum nas gravações é o "dobramento", ou seja, momento no qual instrumentos distintos executam a mesma melodia, tanto faz se em uníssono ou por abertura de oitavada (MENEZES JR., 2016, p. 50). "Clube da esquina ${ }^{\circ}$ 2", a canção, é um exemplo claro desse procedimento, que ocorre desde o início de sua carreira, tal como presente em 1969, na gravação de "Sentinela" (MENEZES JR., 2016, p. 309).

Esse tipo convívio é explícito na música "Minas", esse "caso, quase-didático, da abertura" (GUERALDO, 2017, p. 80) do álbum Minas (1975), no procedimento que Sérgio Molina batizou de telhagem: 


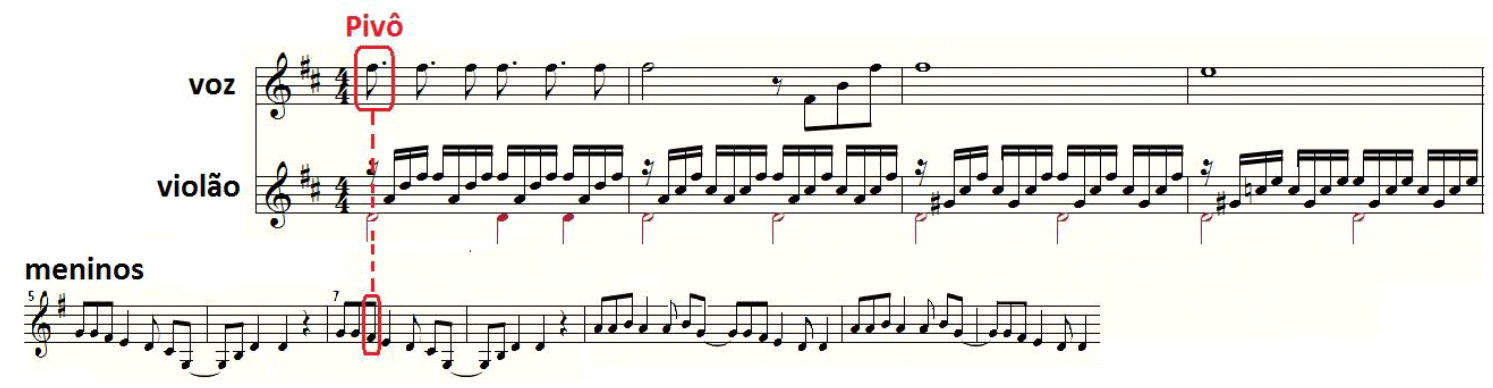

Fig. : Processo de Telhagem no fonograma "Minas” (MOLINA, 2015, p.84)

Aqui o fonograma começa com o coro dos meninos cantando a melodia da décima faixa do LP, a canção "Paula e Bebeto", a que se segue a melodia principal em outra tonalidade, sendo que ambos os universos possuem uma nota em comum (o fa\#). O que explicita que a união dos distintos não se faz por justaposição, mas por um embricamento sutil que busca a igualdade na diferença.

\section{Mistura das misturas e a sonoridade específica}

Pelo que foi apresentado, fica estabelecido que, tanto nas estórias de Rosa quanto nas gravações de Milton, a forma interna, o teor (BENJAMIN, 2011, p. 13), que sustentam as obras podem ser expostos como se estruturando por uma relação dialética entre pares opostos - falta, evidente, especificá-las, para, somente então, vislumbrar as diferenças que permitem a comparação - que genericamente "parece apontar" "para a mistura das misturas", expressão utilizada por José Antonio Pasta Jr. (2011, p. 150) em um estudo sobre Rosa,

Realismo documental $e$ um mapa mágico ficcional, romance de formação burguês $e$ narração baseada na tradição oral, esclarecimento $e$ pacto com o demo; do lado de Rosa. Do outro, de Milton: expressões musicais baseadas na tradição oral (congada) $e$ aquela que nasceu com a industrialização mundial (o rock), fonogramas autônomos $e$ a constante citação interna aos discos, avião $e$ carro de boi, trechos atonais $e$ composições tonais - parênteses: assim como o romance enquanto forma tem seu nascimento indissociável do moderno mundo da mercadoria (LUKÁCS, 2000), o desenvolvimento do tonalismo e do temperamento enquanto maneira de organização dos sons traz a mesma marca de nascença (ADORNO. 2009). Novamente com a palavra, Pasta Jr.:

A matriz de todas as misturas: a vigência simultânea de dois regimes da relação sujeito objeto - um que supõe a distinção entre sujeito e objeto ou, se se quiser, o mesmo e o outro, e um segundo que supõe a indistinção de ambos. (...) [o que] determina a lógica de base do livro [trata-se do Grande Sertão] e responde pelo conjunto de sua estruturação formal. (...) essa junção inextricável, em um mesmo princípio, de 
movência obrigatória e fixidez inamovível, de metamorfose contínua e pura repetição, indica para a fórmula de base que aqui se trata de identificar, o estatuto da contradição insolúvel (2015, p. 150-151 - interpolações minhas).

Essa é a síntese do poetificado que permitirá a comparabilidade, para voltar aos termos benjaminianos, de ambas as produções: a coexistência mútua de duas séries de determinações que são excludentes entre si, mas que de alguma maneira conseguem conviver no interior das obras. Como já deve estar implícito, as soluções encontradas para essa "contradição insolúvel" implicarão em diferentes propostas de leitura da realidade.

Arrisco dizer que as obras que mais claramente explicitam essa lógica estética não são as mais aclamadas pela fortuna crítica, a saber, é no conjunto das estórias que compõem o Corpo de Baile, cuja publicação é no mesmo ano de Grande Sertão, 1956, e no inusitado "álbum duplo" Minas e Geraes, lançados separadamente nos anos de 1975 e 1976, respectivamente, mas que apresentam traços de contiguidade tão marcantes que formam um único projeto (NUNES, 2005, p. 40; VILELA, 2010, p. 26; GARCIA, 2006, p. 204-205; GUERALDO, 2017, p. 16-44).

A unidade de Corpo de baile é mais evidente, inclusive por ter sido inicialmente publicado como um livro único, sendo posteriormente desmembrado em três: Manuelzão e Miguilim; No Urubuquaquá, no Pinhém e Noites do sertão. Das personagens que se repetem ao longo das sete estórias, nos locais pelos quais a(s) trama(s) narrativa(s) se desenrola(m), das múltiplas referências que umas fazem às outras, em suma:

\begin{abstract}
A obra percorre, da primeira à última novela, toda a organização social do sertão do gado: parte da pobreza mais anômica para chegar ao meio proprietário, passando pela realidade de vaqueiros, enxadeiros, capatazes, pequenos e médios proprietários. Paralelo a esse percurso social, a obra empreende, de "Campo geral" a "Buriti", um percurso pelos modelos textuais que lhe servem de referência na produção de sua forma, mas que são principalmente tematizados pelos textos (BERGAMIN, 2008, p. 10).
\end{abstract}

A ligação entre os LPs Minas e Geraes começa pelo nome, que juntos formam o estado que Milton Nascimento assumiu como seu; a capa do segundo é contracapa do primeiro; o último som do primeiro disco (um acorde orquestral de Lá-maior) é o primeiro evento do segundo; a música de abertura de Minas, também intitulada "Minas", é a mesma composição que encerra o Geraes, que agora conta com letra de Ronaldo Bastos e transmuta-se em "Minas Geraes". Além disso, recursos musicais, paisagens e figuras poéticas aparecem inúmeras vezes ao longo das faixas que compõem esse álbum "duplo". O tema da memória, para ficar em um único exemplo, está claramente presente 
em três das onze músicas de Minas ("Beijo partido", "Saudades dos aviões da Panair" e "Ponta de Areia") e em cinco das doze de Geraes ("Fazenda", "Volver a los 17", "Menino", "Viver de amor" e "Minas Geraes").

Se em Guimarães o material social é eminentemente sertanejo, “o sertão do gado" em oposição à vida supostamente esclarecida e civilizada da cidade; é no pêndulo entre esses mundos que se perfaz a unidade da diferença de Minas-Geraes. Evidente que esse outro ausente nas novelas é uma presença ativa, mesmo que velada. Basta lembrar do interlocutor mudo de Riobaldo, o doutor. Em Corpo de Baile, essa trânsito entre a roça sertaneja e a modernidade tecnológica citadina é claramente marcada na travessia transformadora do pequeno Miguilim, da primeira estória do livro, "Campo geral", em Miguel, personagem aparentemente principal, mas logo posto em segundo plano, da novela "Buriti", que encerra a obra.

No(s) disco(s), essa distância entre esses dois regimes aparece, inicialmente, como bem delimita a cada um dos LPs. Minas parece orbitar em sonoridades e temas vinculados à industrialização, aos aglomerados urbanos, muito devido ao predomínio do clima roqueiro - "a principal inovação do rock foi tecnológica", nos lembra Hobsbawn (1990, p. 20), por conseguinte, indissociável dos avanços tecnológicos, do capital industrial (HERZHAFT, 1989) - como se nota nos riffs, na instrumentação, nos ritmos. O Geraes, por seu turno, tem na determinação recíproca entre personagem e comunidade (LUKÁCS, 2000, p. 69) seu eixo de estabilidade, nas sonoridades baseadas na tradição oral o seu germe criador. Para ficar no mesmo âmbito, basta indicar o predomínio da instrumentação ligada à moda de viola - "um elo com a tradição, com o meio rural e seus códigos subjetivos." (VILELA, 2000, p. 64) - ou à música tradicional andina, como o charango e o quarto venezuelano (GUMÍ, 2005). Evidente que a simples aparição desses sons não implica em invocar tais matrizes históricoestéticas. A maneira como as diversas figuras poéticas são tratadas em cada LP também articulam essa conexão, como se nota na mudança do foco narrativo: "Ao passo que no LP Minas há um predomínio de um ponto de vista individual e uma atmosfera de decadência, nos Geraes sobressai a visão sobre uma maneira coletiva de viver, marcada pelo signo da dissolução" (GUERALDO, 2017, p. 59).

Tanto no romance quanto nos álbuns, no entanto, essa demarcação entre o outro e o mesmo, o daqui e o de lá, campo e cidade, comunidade isolada e sociedade integrada; enfim, a separação entre esses "dois regimes", na formulação de Pasta Jr., não existe plenamente. Sem exatamente se confundirem, esses opostos estão impregnados, são duas determinações do mesmo processo:

Claro que essa demarcação não é plena, há várias intersecções entre esses dois polos, como a presença do pontear da viola em "Paula e Bebeto", música de Milton Nascimento com letra de Caetano Veloso, e da linha de baixo em "Promessas do sol", novamente

Revista Crioula - $\mathbf{n}^{\circ} \mathbf{2 6}$ - Relações entre literatura e música na produção de língua portuguesa 
música de Milton Nascimento desta vez com letra de Fernando Brant, que apesar de não terem a primazia na criação da atmosfera musical nos fonogramas, trazem uma sonoridade alheia ao universo criado - exatamente aquela presente no outro disco (GUERALDO, 2017, p. 56)

O narrador de Corpo de baile, entrando e saindo de personagens, erudito e regional, urbano e sertanejo, apresenta sempre as duas faces opostas simultaneamente; ele é interior e exterior ao sertão no mesmo gesto narrativo (BERGAMIN, 2008, p. 237).

É por meio desse jogo que separa ao unificar que deve-se enxergar a dinâmica social que lhes serviram como matéria-prima. Um primeiro aspecto a se considerar é que quanto mais "para dentro" do mapa, mais no sertão se está e, por derivação, mais afastado da cidade, mais distante do outro. Outra semelhança estrutural entre Corpo de baile e Minas-Geraes: ambos percorrem um trajeto semelhante, saem do sertão e a ele retornam. A obra rosiana se inicia "longe, longe daqui, muito depois da Vereda-do-Frango-d'Água e de outras veredas sem nome ou pouco conhecidas, em ponto remoto, no Mutúm" (ROSA, 1984, p. 13). A travessia, no entanto, se faz na cidade - Miguel volta como veterinário estudado, doutor, portanto - mesmo que nós, os leitores, não tenhamos acompanhado seu desenvolvimento narrativo. Assim como em Grande sertão, o livro é e não-é, ao mesmo tempo, um romance de formação (BERGAMIN, 2008, p. 237-238).

A vida no Mutum era materialmente miserável, sem dúvida, além da fúria paterna constante; no entanto era o mundo da amizade, do Dito. A condição material do Buriti Bom é muito melhor, mas está plenamente ameaçada, não tanto pela técnica - encarnada em Miguel -, ou em Nhô Gualberto, o vizinho e sócio de Iô Liododo, ambos proprietários; antes, no que o primeiro representa, "o espírito utilitarista do capitalismo" (RONCARI, 2008, p. 75.); afinal, apesar do moralismo perante a vida sexual noturna e fingidamente desconhecida de Liodoro, ele quer dominar pela coisa, tem gula pelo crescimento - tanto que é a ele que Miguel vem prestar seus serviços - que como diz o representante local intimamente vinculado às forças sobrenaturais, chefe Zequiel, que vê em sua alucinação lúcida o perigo do que Roncari chamou de "coisa-criada, que, em circulação, se transforma na senhora destrutiva de seus criadores" (p. 75), ou seja, a mercadoria.

Mas é na figura de Lalinha, moça da cidade, portadora de outros valores, a representante por excelência do outro mundo (BERGAMIN, 2008, p. 272-273) e, em especial, em sua relação com a alegoria do patriarcado, o varão, pai de família e mantenedor da ordem social, Io Liodoro, que a postura de Rosa frente às transformações que aquele mundo está passando se materializa. A dinâmica do capital chegou ao sertão e com ela a dissolução das relações sociais e os costumes mágicos ("A lógica da magia simpática, disseminada por todo o Corpo de baile, em simpatias, benzeduras, 'trabalhos', 
feitiços e profecias, sempre conversa, quando aparece, uma dimensão de eficácia" ((BERGAMIN, 2008, p. 251)), que sustentavam a vida. Dona Lala atua como aquela que irá suspender o conflito entre modernização destruidora e o esclarecimento-mágico (mais uma das contradições rosinas) do sertanejo:

\begin{abstract}
A força da natureza que Lala encontra no Buriti Bom não é para ser negada, ela tem um fundo positivo, pois proliferam ali todos os seres, plantas, bichos e homens, e assim, o lugar regorgita vida; o que precisa, é de receber o esmalte de alma e cultura, dos artifícios humanos trazidos por lala Lalinha, como uma fada madrinha (RONCARI, 2008, p. 78).
\end{abstract}

Em breve voltaremos a esse veredito. Antes, rumemos pelas veredas de Minas e Geraes que, no essencial, são muito parecidas. Os seus respectivos lados A demarcam uma situação de vida interiorana, da roça, do sertão. Após a abertura instrumental, a primeira faixa do LP Minas, desponta "Fé cega, faca amolada", um pop-rock, como atestam o ritmo da pandeirola e a "levada" da guitarra. A parte $\mathrm{B}$ da música reafirma o caráter roqueiro da gravação, pelo riff do contrabaixo e pela bateria que assume o seu papel corriqueiro no gênero. No entanto, a letra da canção tem por mote a contestação, a revolta baseada na faca e na fé, com forte propensão à cristandade, pelo "pão", "vinho" e "irmão" “que, no entanto, ganha contornos locais mais precisos: o já cangaço. Essa situação histórica é a manifestação social que mais claramente associou, no Brasil, uma intenção de revolta, via facão, com um caráter messiânico, religioso" (GUERALDO, 2017, p. 83). Nem seria preciso dizer que o palco dos cangaceiros é o mesmo dos jagunços, o sertão. Além de marcar o início da jornada como sendo o interior do país, o fonograma atualiza a lei estético estrutural que foi estabelecida como a forma interna da obra: o convívio dos contrários, a busca pela síntese impossível de uma contradição insolúvel. O banditismo local cangaceiro com o cosmopolitismo do pop-rock.

Na metade do disco ouve-se em "Trastevere" o verso "a cidade é moderna" (NASCIMENTO, 1975), cuja expressão cancional se assenta em uma atmosfera sonora na qual "o conceito de melodia, harmonia e ritmo teve seu rompimento total" (VILELA, 2000, p. 24); cidade moderna que comporta uma conversa surrealista entre um pai cego que vê e um filho surdo que ouve - bate-papo surreal que ganha forma no "diálogo quase escondido" entre piano e guitarra que acontece na parte C da composição (GUERALDO, 2017, p. 106-7). O fim dessa primeira travessia acontece com a transformação, na canção "Simples", do "ouro" de "água da vida" em "nossa tristeza", fazendo uma possível referência à exploração de ouro e diamante nas Minas do Brasil colônia, dando contornos históricos amplos para essa viagem e, ao mesmo tempo, retornando ao interior do qual partiu. "Mas a canção não pára por aí, a desgraça contemporânea ainda teve o mérito de nos fazer esquecer as 
incontáveis mortes, principalmente de escravos, que foram os pilares dessa 'cidade moderna' ('O sangue da terra/ virou brinquedo')" (GUERALDO, 2017, p. 65).

Muito rapidamente, o trajeto dos Geraes é em tudo semelhante na sua diferença: do convívio intergeracional pleno da canção "Fazenda" (GUERALDO, 2017, p. 164-165) - que obviamente inicia a viagem no interior - desloca-se rumo à América Latina, com a presença da gravação de "Volver a los 17”, de Violeta Parra, para enfim retornar à roça com "Carro de boi”, não para louvar as belezas do local ou dessa dinâmica social em oposição à desregrada e poluída cidade pois "a canção expõe a tensão entre duas vontades, a dos homens e a da 'natureza' (...) [pela qual] estes eram submetidos, em alguma medida, aos ditames na natureza" (GUERALDO, 2017, p. 174). Mas mesmo assim, o mundo coletivo do interior guarda traços de união muito superiores, sob o olhar da obra, do que o desespero do isolamento apresentado pelos aglomerados urbanos, tal como se ouve em "O que será? (À flor da pele)".

Em resumo, a mistura operada por Minas-Geraes parece apontar para determinados aspectos louváveis do mundo interiorano, da roça, do sertão; a saber, a força comunitária que a todos unia mas que guarda suas mazelas, do banditismo contra a fome de "Fé cega, faca amolada" à submissão à natureza de "Carro de boi”. O bom lugar é o impossível convívio imaginado, por conseguinte, a criação de um não-lugar que agregaria a comunidade e a emancipação - a dominação da natureza ou o esclarecimento, caso se queira.

\section{Consenso e suspensão}

Tem-se, então, que enquanto em Rosa há a suspensão dos problemas sociais pela tentativa de historicização do caráter mítico do sertanejo, processo literário no qual se busca um esclarecimento jagunço (tal como visto do famoso caso do tribunal jagunço de Grande sertão), na força comunitária que pára o tempo no caráter cíclico das relações sociais, que na sua violência explícita - como a dos jagunços ou política, como as do coronel Liodoro - mantém a ordem social, ao contrário dos "fios invisíveis" (MARX, 1985, p. 158) do capital:

\footnotetext{
a questão é que, mudando-se a perspectiva no ato mesmo de buscar incorporá-la - o que idealiza a 'cultura popular', vista, em alguma medida, como universo infenso à ideologia -, o olhar compassivo do escritor implica também adesão mítica e suspensão dos problemas de ordem social que envolveriam proprietários e homens pobres (PACHECO, 2008, p. 181).
}

Em Milton, por sua vez, ouve-se a busca pelo consenso, a criação de um não-lugar - um 
reposicionamento da contradição sem conflito proposta pela bossa-nova (GARCIA, 1999) - que imaginariamente existiu no qual os laços comunitários ainda podiam conviver com a dinâmica fantasmagórica que rege a vida de todos na falsa igualdade, a exploração da vida capitalista.

Essa diferença bem pode significar dois lados de um mesmo tipo de crítica conservadora (porque busca num passado idealizado a solução) para os males da entificação do capital em solo nacional que será sempre incompleta por ser "hiper-tardia", assentada no latifúndio agroexportador, "sem nunca romper com sua condição de país subordinado aos pólos hegemônicos" (CHASIN, 2000, p. 17). Essa é a marca da "via colonial”, categoria proposta por José Chasin para pensar a "mediação necessária e objetiva entre a universalidade do capitalismo e determinações singulares" (2000, p. 17). Por falta de espaço, me contento em explicitar uma das consequências dessa leitura histórico-filosófica: seremos sempre incompletos - marca impregnada em nossa tradição literária (PASTA JR, 2015) -, nunca uma democracia-liberal, inclusive pelas elites dirigentes locais, que sequer pensaram algum dia em propor o fim das atividades agrárias herdadas dos tempos coloniais (CHASIN, 2000, p.124 e OLIVEIRA, 2013, p. 148-149) - a burguesia nacional muda mantendo, tal como já condensado nas obras de maturidade de Machado de Assis (SCHWARZ, 2012).

As obras de Milton e Rosa são, desse modo, duas respostas distintas, mas irmãs, ao avanço contraditório do capitalismo em solo nacional, a tal modernização conservadora; pois só realiza o novo, essencial à acumulação, ao manter o velho, as relações sociais e a estrutura de poder de matriz colonial (OLIVEIRA, 2013, p.60). Talvez as quase duas décadas que os separam tenham colocado justamente essa diferença na igualdade entre essas respostas que reconhecem as mazelas, mas ainda guardam uma esperança não revolucionária.

\section{Referências bibliográficas}

ADORNO, Theodor W. Filosofia da nova música. Trad. Magda França. São Paulo: Perspectiva, 2009.

ARRIGUCCI JR., Davi. O mundo misturado: romance e experiência em Guimarães Rosa. In: Novos estudos CEBRAP, São Paulo (40): 7-29, nov. 1994. Disponível em: https:/edisciplinas.usp.br/pluginfile.php/4457413/mod_resource/ content/1/Davi\%20Arrigucci\%20-\%200\%20mundo\%20misturado.pdf. Acesso em: 5 nov.2020.

BENJAMIN, Walter. Dois poemas de Friederich Hölderlin. In: Escritos sobre mito e linguagem. Trad. Susana kampff Lages e Ernani Chaves. São Paulo: Duas Cidades/Ed. 34, 2011. p. 13-48.

. Linguagem, tradução, literatura. Trad. João Barrento. Belo Horizonte: Authêntica, 2018.

BERGAMIN, Cecília de Aguiar. Dansadamente: a unidade do Corpo de Baile de João Guimarães Rosa. Dissertação de mestrado (Literatura brasileira). São Paulo: USP, 2008.

BOLLIE, Willie. Grandesertão.br: o romance de formação do Brasil. São Paulo: Ed. 34, 2004.

CANDIDO, Antonio. O homem dos avessos. In: Tese e Antítese. $4^{\circ}$ ed. São Paulo: T.A. Queiroz, 2002.

Revista Crioula - $\mathbf{n}^{\circ} 26$ - Relações entre literatura e música na produção de língua portuguesa

$2^{\circ}$ Semestre 2020 
CHASIN, José. A miséria brasileira: 1964-1994 - do golpe à crise social. Santo André: Ad Hominem, 2000.

DINIZ, Sheyla Castro, "Nuvem cigana": a trajetória do Clube de Esquina no campo da MPB. Dissertação de mestrado (Sociologia), Campinas: UNICAMP, 2012.

GARCIA, Luiz Henrique Assis. Na esquina do mundo: trocas culturais na música popular brasileira através da obra do Clube da Esquina (1960-1980). Tese de doutorado (História), Minas Gerais: UFMG, 2006.

GARCIA, Walter. Bim bom: a contradição sem conflitos de João Gilberto. São Paulo: Paz e Terra, 1999.

GUMÍ, Albert. Sakapatú: un viaje por la música andina. Barcelona: Fundación “la Caixa”, 2005.

HERZHAFT, Gérard. Blues. Trad. de Nícia Adan Bonatti. Campinas: Papirus, 1989.

HOBSBAWM, Eric J. História social do jazz. Trad. de Angela Noronha. Rio de Janeiro: Paz e Terra, 1990.

LUKÁCS, Georg. A teoria do romance: um ensaio histórico-filosófico sobre as formas da grande épica. Trad. José Marcos Mariani de Macedo. São Paulo: Duas cidades/Ed. 34, 2000.

MARX, Karl. O capital: crítica da economia política. Livro Primeiro. Tomo II. Trad. de Regis Barbosa e Flávio R. Kothe. $3^{\circ}$ ed. São Paulo: Nova Cultural, 1985.

MENEZES JÚNIOR, Carlos Roberto Ferreira de. Os elementos composicionais do Clube da Esquina como alimentadores de processos criativos de arranjos vocais de canções populares brasileiras. Tese de doutorado (música). São Paulo: USP, 2016.

MOLINA, Sérgio A. A composição de música popular cantada: a construção de sonoridades e a montagem dos álbuns no pós-década de 1960. Tese de Doutorado (Música). São Paulo: USP, 2015.

NASCIMENTO, Milton. Milton Nascimento. Codil, 1967 (relançado pela Som Livre com o título de Travessia, em 1978).

. Milton Nascimento. EMI-Odeon, 1969.

. Milton. EMI-Odeon, 1970.

. Minas. EMI-Odeon, 1975

Geraes. EMI-Odeon, 1976

NASCIMENTO, Milton; BORGES, Lô. Clube da Esquina. EMI-Odeon, 1972.

NUNES, Thais dos Guimarães Alvim. A sonoridade especifica do clube da esquina. Dissertação de mestrado (Música), Campinas: UNICAMP, 2005.

OLIVEIRA, Francisco de. Crítica à razão dualista/O ornitorrinco. São Paulo: Boitempo, 2013.

PACHECO, Ana Paula. Jagunços e homens livres pobres: o lugar do mito no Grande sertão. In: Novos estudos CEBRAP, São Paulo (81): 179-188, jul. 2008. Disponível em: https://www.scielo.br/pdf/nec/n81/13.pdf. Acesso em: 5 nov.2020

PASTA JÚNIOR. José Antonio. "O romance de Rosa". In. Formação supressiva: constantes estruturais do romance brasileiro. Tese de livre Livre-Docência (Literatura Brasileira). São Paulo: USP, 2011.

RONCARI, Luiz. Patriarcalismo e dionisismo no santuário do Buriti Bom. In. Revista do ieb, São Paulo (46): 43-80, fev. 2008.

ROSA, João Guimarães. Manuelzão e Miguilim (Corpo de baile). $9^{\circ}$ ed. Rio de Janeiro: Nova Fronteira, 1984. Grande Sertão: veredas. Rio de Janeiro: Nova Aguilar, 1994. 
. Sagarana . Rio de Janeiro: Nova Fronteira, 2001a.

. Noites do sertão (Corpo de baile). $9^{\circ}$ ed. Rio de Janeiro: Nova Fronteira, 2001b.

SCHLEGEL, Friedrich. O dialeto dos fragmentos. Trad. Márcio Suzuki. São Paulo: Iluminuras, 1997.

SOUSA, Harlon Homem de Lacerda. As arquitetônicas sertanejas da ficção de João Guimarães Rosa. Tese de doutorado (Letras) Fortaleza: UFC, 2018.

SCHWARZ, Roberto. Um mestre na periferia do capitalismo: Machado de Assim. $2^{\circ}$ Ed. São Paulo: Duas cidades/Ed. 34, 2012.

VILELA, Ivan. A arte de pontear viola. Brasília, Curitiba: Ed. Autor, 2000.

. Nada ficou como antes. In: Revista USP, São Paulo (87): 14-27, set./out./nov. 2010. Disponível em:

http://www.revistas.usp.br/revusp/article/view/13827/15645. Acesso em: 5 nov.2020 


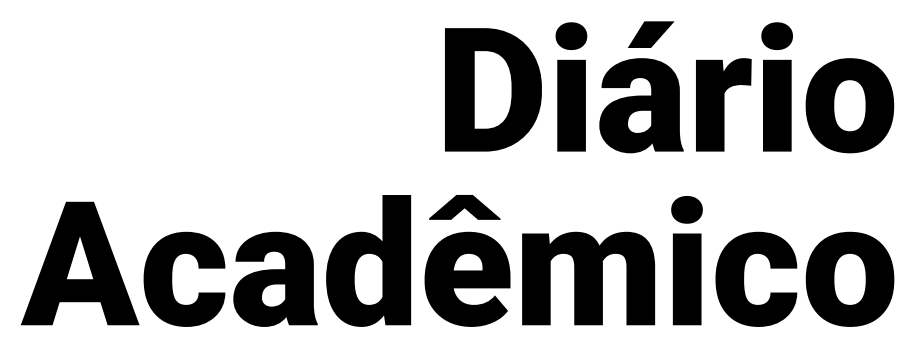

Revista Crioula - $\mathbf{n}^{\circ} \mathbf{2 6}$ - Relações entre literatura e música na produção de língua portuguesa $2^{\circ}$ Semestre 2020 